\title{
Pengaruh Variasi Waktu Tahan Austenisasi dengan Pendinginan Cepat terhadap Kekerasan dan Ketangguhan Baja AISI 1045
}

\author{
Ediman Ginting*, Endarmoko and Roniyus Marjunus \\ Received: 4 Feb., 2020 | Accepted: 11 Feb., 2020 | Published: 16 June, 2020 | DOI: 10.22146/jfi.v24i1.54038
}

\begin{abstract}
Ringkasan
Telah direalisasikan Pengaruh Variasi Waktu Tahan Austenisasi dengan Pendinginan Cepat terhadap Kekerasan dan Ketangguhan Baja AISI 1045. Penelitian ini dilakukan untuk mengetahui bagaimana pengaruh waktu tahan austenisasi dengan variasi waktu tahan 0 menit, 15 menit, 25 menit, dan 40 menit dilanjutkan pendinginan cepat terhadap kekerasan dan ketangguhan Baja AISI 1045. Baja AISI 1045 diberi perlakuan panas menggunakan furnace dengan suhu austenisasi $830^{\circ} \mathrm{C}$, kemudian didinginkan cepat dengan air \pm 3 detik. Baja AISI 1045 diuji menggunakan Universal Hardness Tester Rockwell $C$ untuk uji kekerasan dan Mesin Uji Impak untuk uji ketangguhan. Hasil penelitian diperoleh bahwa nilai kekerasan Baja AISI 1045 meningkat dan nilai ketangguhan menurun. Nilai rata-rata kekerasan terbesar diperoleh pada waktu tahan 40 menit sebesar 75,30 $\pm 0,9 \mathrm{HRC}$. Nilai rata-rata ketangguhan terkecil diperoleh pada waktu tahan 40 menit sebesar $0,85 \pm 0,04 \mathrm{~J} / \mathrm{mm}^{2}$.
\end{abstract}

Kata Kunci : Baja AISI 1045, waktu tahan, austenisasi, kekerasan, ketangguhan.

Abstract

The effect of Austenization Holding Time Variation with Rapid Cooling has been realized on the hardness and toughness of AISI 1045 steel. This research was conducted to find out how the effect of austenization holding time with variations in holding time 0 minutes, 15 minutes, 25 minutes, and 40 minutes followed by rapid cooling to hardness and toughness AISI 1045 steel. AISI 1045 steel is heat treated using a furnace with austenization temperature of $830^{\circ} \mathrm{C}$, then cooled quickly with water \pm 3 seconds. AISI 1045 steel was tested using Rockwell C Universal Hardness Tester for hardness test and Impact Test Machine for toughness test. The results showed that the value of AISI 1045 Steel hardness increased and the value of toughness decreased. The highest average value of hardness was obtained at a 40 minute holding time of $75.30 \pm 0.9 \mathrm{HRC}$. The average value of the smallest toughness was obtained at 40 minutes holding time of $0.85 \pm 0.04 \mathrm{~J} / \mathrm{mm}^{2}$.

Keywords: AISI 1045 steel; holding time; austenization; hardness; toughness.

\section{PENDAHULUAN}

Dalam dunia industri saat ini, baja merupakan material yang banyak digunakan dalam bidang teknik. Baja merupakan material yang paling banyak digunakan sebagai bahan industri, karena baja mempunyai sifat-sifat fisis dan mekanis yang bervariasi. Baja sebagai material utama untuk menunjang berbagai keperluan industri terus

\footnotetext{
*Correspondence: gintingediman@gmail.com

Jurusan Fisika, Fakultas Matematika dan IImu Pengetahuan, Universitas Negeri Lampung, Yogyakarta, Indonesia

Full list of author information is available at the end of the article

${ }^{\dagger}$ Equal contributor
}

meningkat, dimulai dari industri otomotif, perkapalan, permesinan, dan industri lainnya [1].

Baja adalah campuran dari besi dan karbon, di mana unsur karbon menjadi dasar campurannya [2]. Kandungan unsur karbon dalam baja berkisar antara $0.2 \%$ hingga $2.1 \%$ sesuai jenis baja itu sendiri [3]. Baja karbon AISI 1045 merupakan jenis baja yang klasifikasi dalam baja paduan karbon sedang yang umumnya digunakan sebagai bahan utama pada mesin seperti poros, gear, dan batang penghubung piston pada kendaraan bermotor. Baja AISI 1045 diberi nama menurut standar American Iron and Steel Institue di mana angka $1 \mathrm{xxx}$ menunjukkan baja dengan kadar karbon, kode 10xx yang terdapat pada 
spesifikasi karbon merupakan kadar karbon steel dan nomor 45 yang terdapat setelah kode 10 menunjukkan kadar karbon yang terkandung dalam baja dengan persentase $0,45 \%$. Oleh karena itu baja ini merupakan baja dengan kadar karbon sedang [4].

Proses perlakuan panas (heat treatment) dapat membentuk (mengubah) sifat besi atau baja dari yang mudah patah menjadi lebih kuat atau juga dapat mengubah sifat baja dari yang lunak menjadi sangat keras. Heat treatment merupakan proses kombinasi antara pemanasan dan pendinginan terhadap logam atau paduan dalam keadaan padat untuk jangka waktu tertentu yang dimaksudkan untuk memperoleh sifat-sifat tertentu pada logam atau paduan [5]. Baja karbon dan baja paduan rendah membutuhkan waktu tahan selama 5-15 menit pada proses perlakuan panas [6].

Menurut penelitian Lestari tahun 2012 [7], waktu tahan sangat berpengaruh terhadap nilai kekerasan baja karbon sedang. Pada penelitiannya, digunakan baja pegas daun SUP JIS No. 1249 dengan 3 variasi suhu austenisasi yaitu $780^{\circ} \mathrm{C}, 830^{\circ} \mathrm{C}$ dan $880^{\circ} \mathrm{C}$ dengan masing-masing waktu tahan selama 20', 40', dan 60'. Nilai kekerasan tertinggi diperoleh sebesar 62,7 HRC dengan suhu $780^{\circ} \mathrm{C}$ dan waktu tahan $20^{\prime}$, sedangkan nilai kekerasan terendah sebesar 58,6 HRC dengan suhu $830^{\circ} \mathrm{C}$ dan waktu tahan $60^{\prime}$. Oleh sebab itu dalam penelitian ini akan digunakan Baja AISI 1045 yang diberi perlakuan panas dengan suhu austenisasi $830^{\circ} \mathrm{C}$. Pada asutenisasi diberikan 4 variasi waktu tahan yaitu 0', 15', 25', dan 40'. Kemudian dilanjutkan dengan pendinginan cepat menggunakan media air sebanyak 10 liter. Hal ini dilakukan untuk mengetahui pengaruh perlakuan yang diberikan terhadap kekerasan dan ketangguhan Baja AISI 1045.

\section{METODE PENELITIAN}

Alat dan bahan yang digunakan dalam penelitian ini yaitu Baja AISI 1045, alat pemotong sampel, furnace, air, Universal Hardness Tester Rockwell C, mesin uji impak. Pada penelitian ini, sampel dipotong dengan ukuran $20 \mathrm{~mm} \times 20 \mathrm{~mm}$ untuk uji kekerasan sebanyak 13 sampel dan $55 \mathrm{~mm} \times 10 \mathrm{~mm} \times 10 \mathrm{~mm}$ untuk uji ketangguhan sebanyak 13 sampel. Sampel untuk uji ketangguhan dibuat takikan seperti Gambar 1.

Sampel yang sudah dipotong kemudian diberi perlakuan panas yang kemudian didinginkan cepat. Siklus perlakuan panas pada Baja AISI 1045 dapat dilihat pada Gambar 2.

Prosedur penelitian dapat dilihat pada Gambar 3.

\section{HASIL DAN PEMBAHASAN}

\subsection{Hasil Uji Kekerasan Baja AISI 1045}

Data hasil uji kekerasan Baja AISI 1045 dapat dilihat pada Tabel 1.

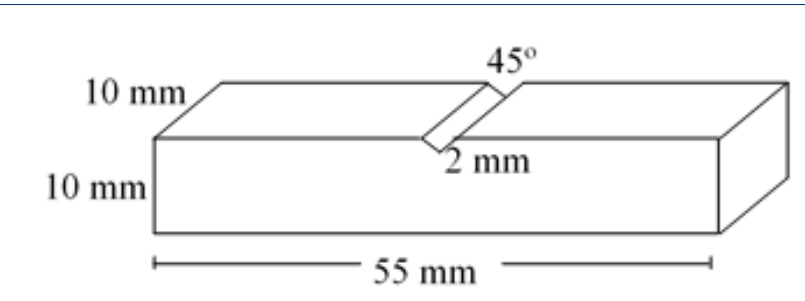

Gambar 1: Bentuk sampel uji ketangguhan.

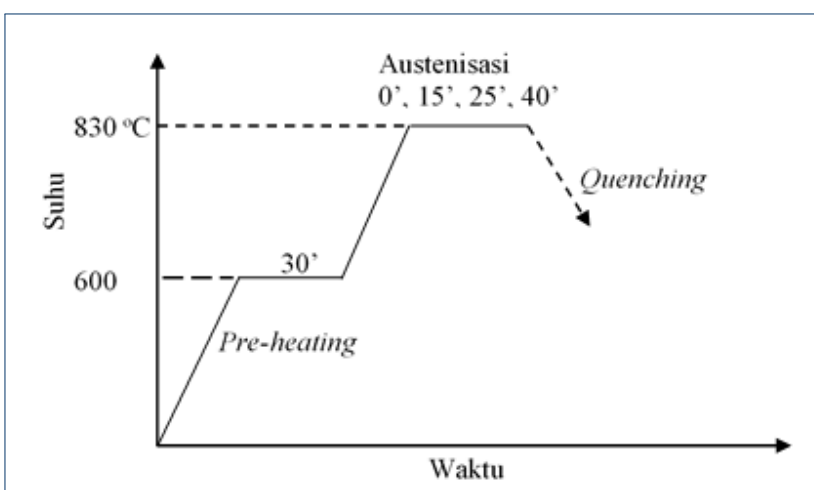

Gambar 2: Siklus perlakuan panas pada Baja AISI 1045.

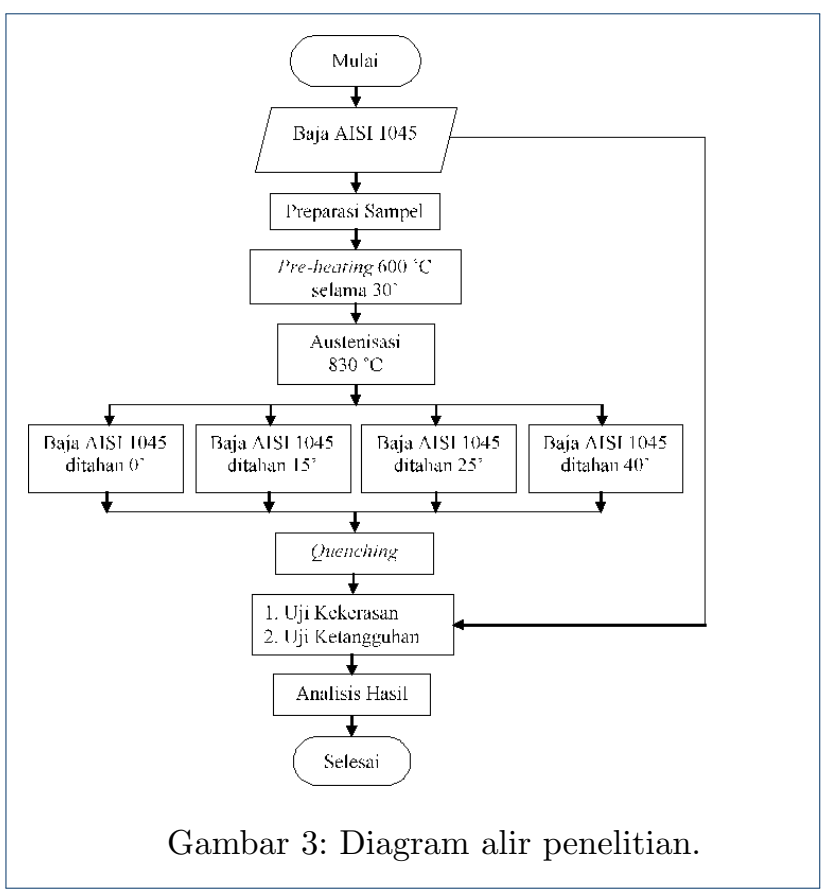

Dari Tabel 1, dapat dilihat bahwa waktu tahan yang diikuti pendinginan cepat sangat memengaruhi nilai kekerasan baja. Nilai kekerasan baja yang mendapatkan perlakuan lebih besar dibandingkan kekerasan Baja Tanpa Perlakuan. Seperti yang 
Tabel 1: Data uji kekerasan Baja AISI 1045

\begin{tabular}{cccc}
\hline Kode Sampel & No & Nilai Kekerasan (HRC) & Rata-rata (HRC) \\
\hline Tanpa & - & 15 & 15 \\
Perlakuan & 1 & 23 & \\
AISI 1045 0' & 2 & 22 & $21 \pm 1$ \\
& 3 & 19 & \\
AISI 1045 15' & 1 & 60 & $56 \pm 2$ \\
& 2 & 53 & \\
AISI 1045 25' & 3 & 54 & $68 \pm 3$ \\
& 2 & 70 & \\
AISI 1045 40' & 3 & 62 & $75,3 \pm 0,9$ \\
& 2 & 71 & \\
\hline
\end{tabular}

dikatakan oleh Haryadi (2005) [8] bahwa perlakuan panas memiliki tujuan untuk meningkatkan kekerasan dari baja. Selain itu, proses pemanasan di atas suhu kritis dan kemudian diikuti pendinginan cepat dapat meningkatkan kekerasan dari baja. Dikatakan oleh Sutiyoko (2014) [9] bahwa suatu baja yang dipanaskan di atas suhu kritis dan ditahan dalam waktu tertentu akan membentuk struktur austenit, kemudian didinginkan secara cepat akan mengubah struktur austenit menjadi martensit. Strukur martensit ini yang membuat baja menjadi lebih keras. Kenaikan nilai kekerasan Baja AISI 1045 ditunjukkan juga pada Gambar 4.

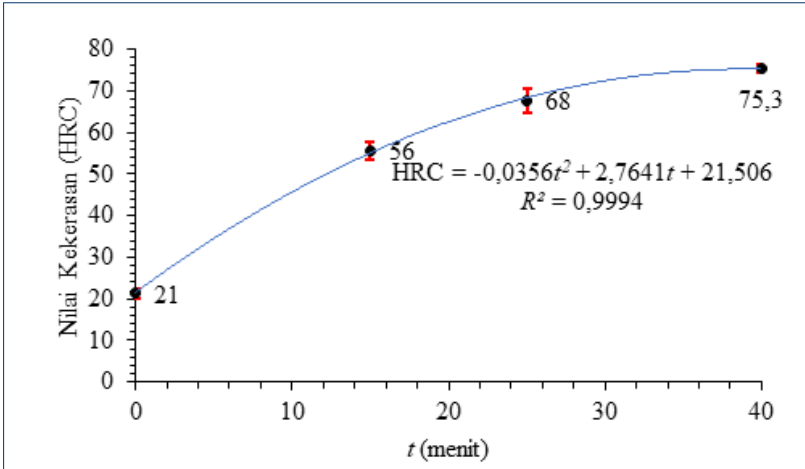

Gambar 4: Grafik nilai kekerasan Baja AISI 1045.

Dari Gambar 4, dapat dilihat bahwa nilai kekerasan maksimum diperoleh pada Baja AISI dengan waktu tahan 40 menit. Pada Gambar 4, ditampilkan trendline dari Ms. Excel dengan bentuk polynomial kuadrat dua sehingga diperoleh persamaan seperti pada Pers. 1.

$$
H R C=-0,356 t^{2}+2,7641 t+21,506
$$

engan $\mathrm{HRC}=$ nilai kekerasan baja (HRC) dan $t=$ waktu tahan (menit). Dari Pers. 1, kemudian diberi masukan dengan $t 60$ menit dan 80 menit. Hal ini digunakan untuk memprediksi nilai kekerasan baja pada waktu tahan 60 menit dan 80 menit. Hasil dari masukan tersebut dapat dilihat pada Gambar 5.

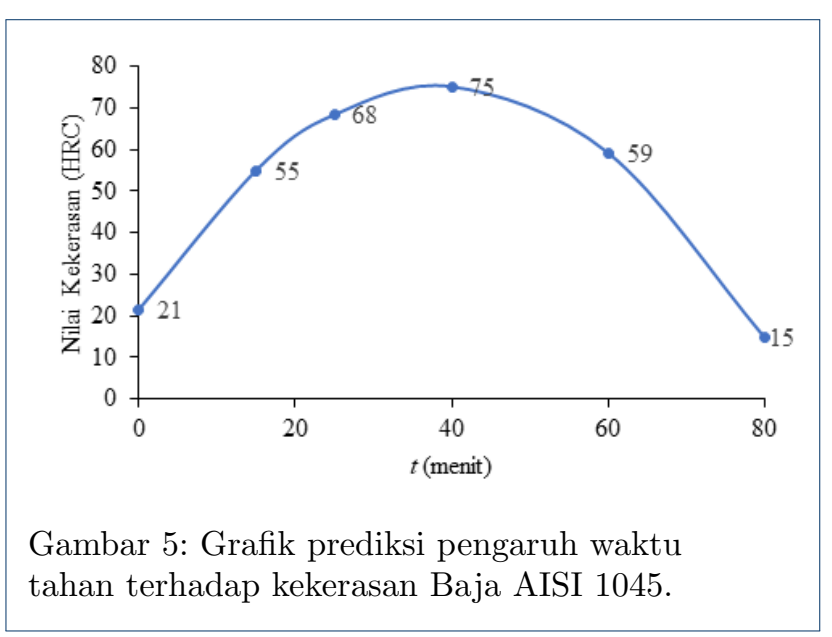

Dari Gambar 5, dapat dilihat bahwa prediksi nilai kekerasan menurun ketika di tahan selama 60 menit dan 80 menit. Prediksi ini sesuai dengan teori yang dinyatakan oleh Dalil (1999) [6] dan Thelning (1984) [1], bahwa waktu tahan yang terlalu lama akan tumbuh butiran yang menyebabkan nilai kekerasan menurun. Penurunan nilai kekerasan baja juga dialami pada penelitian Wibisono dkk (2018) [10] dengan sampel Baja AISI 8655 (karbon sedang) yang diberi perlakuan panas dengan waktu tahan austenisasi selama 30 menit dan 60 menit kemudian didinginkan secara cepat menggunakan air. Hasil nilai kekerasan yang diperoleh Wibisono dkk (2018) [10] dapat dilihat pada Gambar 6.

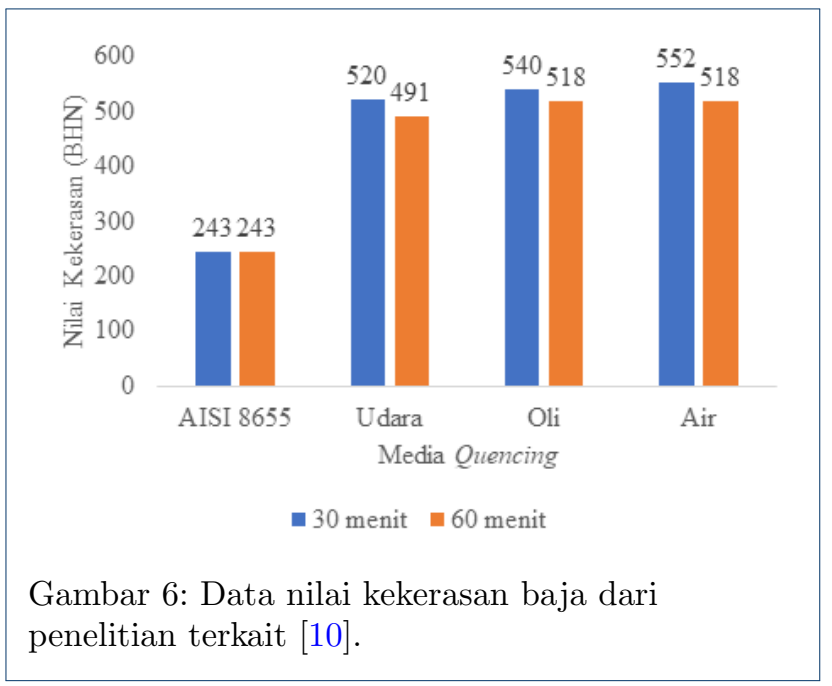


Dari Gambar 6, dapat dilihat pada media quenching air dengan waktu tahan 60 menit mengalami penurunan nilai kekerasan menjadi $518 \mathrm{BHN}$.

\subsection{Hasil Uji Ketangguhan Baja AISI 1045}

Data hasil uji ketangguhan Baja AISI 1045 dapat dilihat pada Tabel 2.

Dari Tabel 2, dapat dilihat bahwa nilai ketangguhan baja yang mendapatkan perlakuan panas diikuti dengan pendinginan cepat mengalami penurunan dibandingkan dengan Raw. Penurunan nilai ketangguhan Baja AISI 1045 dikarenakan banyaknya austenit yang terbentuk ketika baja dipanaskan di atas suhu kritis yang kemudian dilanjutkan dengan pendinginan cepat menghasilkan struktur yang getas bahkan dapat menyebabkan retak [11]. Penurunan nilai ketangguhan Baja AISI 1045 ditunjukkan juga pada Gambar 7.

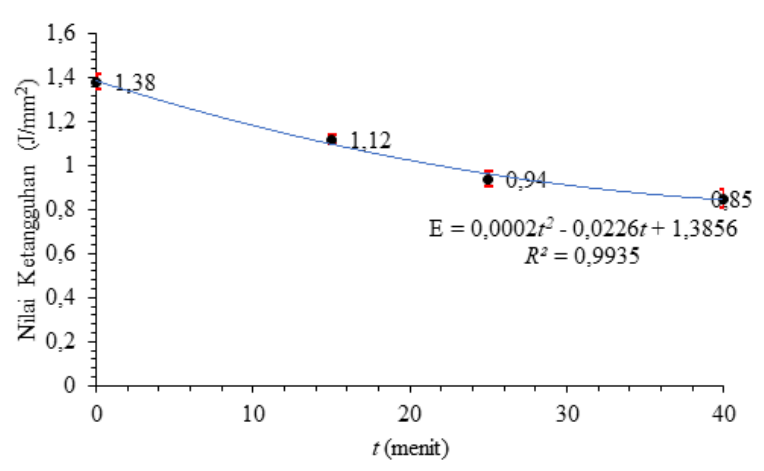

Gambar 7: Grafik nilai ketangguhan Baja AISI 1045.

Dari Gambar 7, dapat dilihat bahwa nilai ketangguhan minimum diperoleh pada Baja AISI 1045 dengaan waktu tahan 40 menit. Pada Gambar 4, ditampilkan trendline dari Ms. Excel dengan bentuk polynomial kuadrat dua sehingga diperoleh persamaan seperti pada Pers. 2.

$$
E=0,0002 t^{2}-0,0226 t+1,3856
$$

dengan $E=$ nilai ketangguhan baja $\left(\mathrm{J} / \mathrm{mm}^{2}\right)$ dan $t=$ waktu tahan (menit). Dari Pers. 2, kemudian diberi masukan dengan $t 60$ menit dan 80 menit. Hal ini digunakan untuk memprediksi nilai ketangguhan baja pada waktu tahan 60 menit dan 80 menit. Hasil dari masukan tersebut dapat dilihat pada Gambar 8 .

Dari Gambar 8, dapat dilihat bahwa prediksi nilai ketangguhan meningkat ketika ditahan selama 80 menit. Prediksi ini sesuai dengan teori yang dinyatakan oleh Thelning (1984) [1], jika waktu tahan

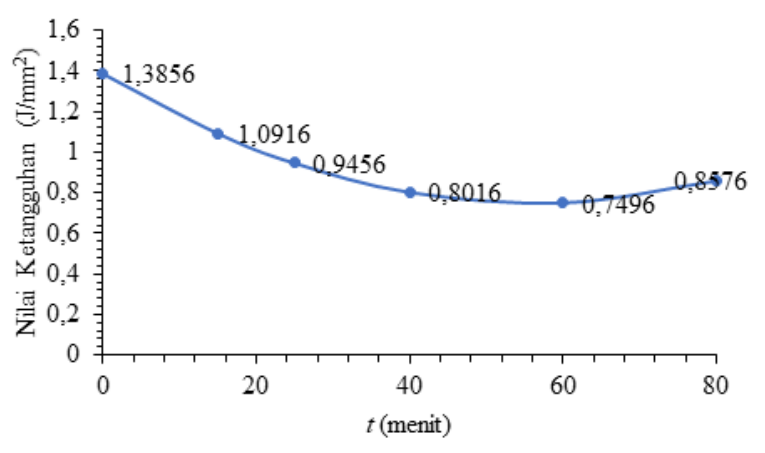

Gambar 8: Grafik prediksi pengaruh waktu tahan terhadap ketangguhan Baja AISI 1045.

terlalu lama makan akan tumbuh butiran yang akan memengaruhi nilai ketangguhan baja. Peningkatan nilai ketangguhan baja dibuktikan oleh Wibisono dkk (2018) [10] menggunakan sampel Baja AISI 8655 yang diberi perlakuan panas dengan waktu tahan austenisasi 30 menit dan 60 menit dan kemudian didinginkan secara cepat. Hasil nilai ketangguhan yang diperoleh Wibisono dkk (2018) [10] dapat dilihat pada Gambar 9.

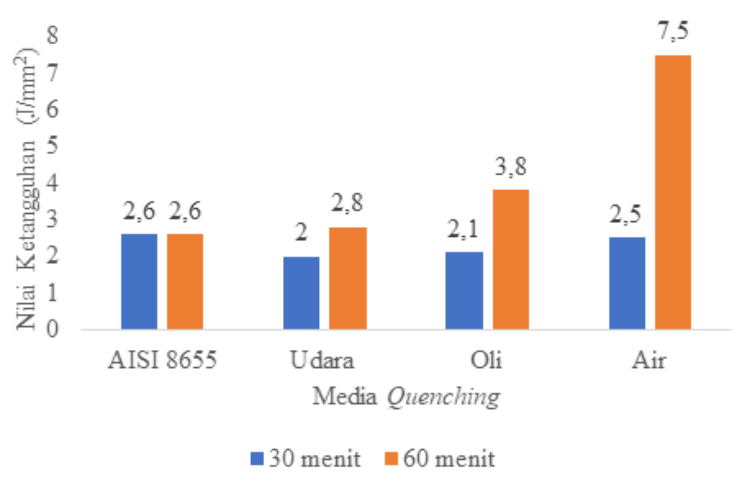

Gambar 9: Data nilai ketangguhan baja dari penelitian terkait [10].

Dari Gambar 9 dapat dilihat pada media quenching air dengan waktu tahan 60 menit mengalami kenaikan nilai ketangguhan menjadi $7,5 \mathrm{~J} / \mathrm{mm}^{2}$.

\section{KESIMPULAN}

Dari hasil penelitian yang telah dilakukan, dapat disimpulkan bahwa nilai kekerasan Baja AISI 1045 meningkat seiring dengan lamanya waktu tahan. Nilai kekerasan terbesar diperoleh pada waktu tahan 40 menit yaitu $75 \mathrm{HRC}, 74 \mathrm{HRC}$, dan $77 \mathrm{HRC}$ dengan rata-rata $75,3 \pm 0,9 \mathrm{HRC}$. 
Tabel 2: Data uji ketangguhan Baja AISI 1045

\begin{tabular}{|c|c|c|c|c|c|c|}
\hline \multirow[t]{2}{*}{ Kode Sampel } & \multirow[t]{2}{*}{ No } & \multicolumn{2}{|c|}{ Dimensi Penampang } & \multirow{2}{*}{ Energi Impak (Joule) } & \multirow{2}{*}{ Nilai Ketangguhan $\left(\mathrm{J} / \mathrm{mm}^{2}\right)$} & \multirow{2}{*}{ Rata-rata $\left(\mathrm{J} / \mathrm{mm}^{2}\right)$} \\
\hline & & $L(\mathbf{m m})$ & $\mathbf{T}(\mathbf{m m})$ & & & \\
\hline \multirow[t]{2}{*}{ Tanpa Perlakuan } & - & 10 & 6,2 & 96 & 1,55 & 1,55 \\
\hline & 1 & 10 & 6,7 & 96 & 1,37 & \\
\hline \multirow[t]{3}{*}{ AISI 1045 0' } & 2 & 10 & 6,6 & 92 & 1,44 & $1,38 \pm 0,03$ \\
\hline & 3 & 10 & 6,9 & 95 & 1,32 & \\
\hline & 1 & 10 & 6,7 & 78 & 1,16 & \\
\hline \multirow[t]{3}{*}{ AISI 1045 15' } & 2 & 10 & 6,8 & 76 & 1,12 & $1,12 \pm 0,02$ \\
\hline & 3 & 10 & 6,9 & 75 & 1,09 & \\
\hline & 1 & 10 & 6,7 & 65 & 0,97 & \\
\hline \multirow[t]{3}{*}{ AISI 1045 25' } & 2 & 10 & 6,8 & 67 & 0,98 & $0,94 \pm 0,03$ \\
\hline & 3 & 10 & 6,9 & 60 & 0,87 & \\
\hline & 1 & 10 & 6,6 & 61 & 0,92 & \\
\hline \multirow[t]{2}{*}{ AISI 1045 40' } & 2 & 10 & 6,9 & 54 & 0,78 & $0,85 \pm 0,04$ \\
\hline & 3 & 10 & 6,9 & 58 & 0,84 & \\
\hline
\end{tabular}

Sedangkan nilai ketangguhan Baja AISI 1045 menurun seiring dengan lamanya waktu tahan. Nilai ketangguhan terkecil diperoleh pada waktu tahan 40 menit yaitu, $0,92 \mathrm{~J} / \mathrm{mm}^{2}, 0,78 \mathrm{~J} / \mathrm{mm}^{2}$, dan 0,84 $\mathrm{J} / \mathrm{mm}^{2}$ dengan rata-rata $0,85 \pm 0,04$.

\section{PENULIS}

1 Ediman Ginting

Dari :

(1) Jurusan Fisika, Fakultas Matematika dan Ilmu Pengetahuan, Universitas Negeri Lampung

2 Endarmoko

Dari :

(1) Jurusan Fisika, Fakultas Matematika dan Ilmu Pengetahuan, Universitas Negeri Lampung

3 Roniyus Marjunus

Dari :

(1) Jurusan Fisika, Fakultas Matematika dan Ilmu Pengetahuan, Universitas Negeri Lampung
Pustaka

1. Thelning KE. Steel and it's heat treatment. London: Butterworths; 1984.

2. Amanto H, Daryanto. Ilmu Bahan. Jakarta: PT Bumi Aksara; 2006.

3. Van V, Lawrence H. Ilmu dan teknologi bahan. Erlangga Jakarta. 2005; .

4. AISI 1045 Medium Carbon Steel; 2012. Available from: http://www . azom. com/article.aspx?articleID $=6130$

5. Purboputro PI. Peningkatan Kekakuan Pegas Daun Dengan cara Quenching. Media Mesin: Majalah Teknik Mesin. 2017;10(1).

6. Dalil M, Adhy P, Ismet I. Pengaruh Perbedaan Waktu Penahanan Suhu Stabil (Holding Time) Terhadap Kekerasan Logam. Jurnal Natur Indonesia II. 1999;1:12-17.

7. Lestari NI. Pengaruh Suhu Pemanasan, Lama Pemanasan dan Pendinginan Secara Cepat Terhadap Sifat Kekerasan dan Mikro Struktur Baja Hypouetectoid [Skripsi]. Universitas Lampung; 2012.

8. Haryadi GD. Pengaruh Suhu Tempering Terhadap Kekerasan Struktur Mikro dan Kekuatan Tarik Pada Baja K-460. Rotasi. 2005;7(3):1-10.

9. Sutiyoko. Perubahan Sifat Mekanik Material Karena Perbedaan Konsentrasi Larutan Garam Nacl Pada Proses Quenching. Jurusan Teknik Pengecoran Logam Politeknik Manufaktur Ceper. 2014;4(1):25-28.

10. Wibisono AT, Ramadhani M, Rochiem R. Effect of Holding Time and Cooling Medium on Microstructure and Hardness of AISI 8655 in Hardening Process. IPTEK The Journal of Engineering. 2018;4(3).

11. Sidney HA. Introduction to physical metallurgy. Prentice-Hall Inc. USA; 1992. 